\title{
Four Types of Guilt and Guilt in the Japanese
}

\author{
Akiko YAMAGISHI \\ Juntendo University
}

\begin{abstract}
The purpose of this study was to classify the main psychological theories about guilt from a cognitive point of view, and to show other types than traditional concepts of guilt. Two criteria were used for classification: whether there was direct interaction with others, and whether one considers only his own act or both his act and the acts of others. The first type of guilt arises from a focus on what one has done, and involves self-reproach for doing wrong. The second involves guilt derived from relatedness, which centers on the other whom one has injured. A third type of guilt results from disequilibrium in an interaction between one person and another. The fourth type is the guilt between no particular relationship, including survivor's guilt. The third type is described in psychological theory which was developed originally in Japan like as the Ajase complex and is presented in some Japanese literary works.
\end{abstract}

Key words: guilt, relatedness, Ajase complex, survivor's guilt, Shusaku Endo

\section{Preface}

Recently in Japan, reports of bullying at school, indiscriminate murder, and crimes that aim to assert one's own identity have dominated the news. Such reports underline fears of an increase in the number of people who consider only their own needs, lack empathic imagination, and feel no guilt or remorse even if they injure others. Furthermore, recent research studies have shown that among youth, consciousness for adhering to society standards has weakened and that young people do not consider deviant behavior so wrong as it was generally considered in the past (Yamagishi, 2002).

For establishing and maintaining a civil society, it is important for people to adhere to accepted standards of behavior and to feel guilty when deviating from them. Guilt has been defined as an agitation-based emotion in which the person experiences fear, worry, anxiety, tension, and the desire to make amends for behaviors perceived as violating internal moral standards (Ferguson, Stegge, Miller, \& Olsen, 1999). Guilt functions to repress anti-social behavior and to encourage individuals to modify their behavior as needed. As well, guilt has the adaptive function of motivating a person to modify or repair the interpersonal break that occurs between one and the other whom one has injured, and to behave pro-socially (Tangney, 1991; Baumeister, Stillwell, \& Heatherton, 1994; Hoffman, 2000). On the other hand, strong guilt may also cause negative feelings and possibly lead to mental illness, such as depression (Tangney, 1991; Baumeister et al., 1994; Bybee, 1998).

In Western society, guilt has been often considered as a problem between God and an individual person, a feeling experienced when one deviates from the standard revealed by God. 
Freud (1923), in his theory of the superego, further expanded upon this notion; guilt is by him, the internalization of a moral standard that parents foster through their discipline. Various postFreudian psychoanalysts have been arguing about guilt from diverse other points of view (O’Connor, Berry, \& Weiss, 2000).

In empirical psychology, the question of guilt has rarely been taken up, although it is an important interpersonal feeling. Nonetheless, since the 1960s, studies of morality have proliferated by Kohlberg and his colleague, but the focus of such studies has been moral cognition or behavior, with scarce mention of guilt.

Recently, however, the importance of emotion has been acknowledged, engendering many new studies. Lewis, Sullivan, Stange, and Weiss (1989) takes up guilt as a negative emotion of self-conscious and self-evaluative emotions. In the 1990s, many studies of guilt have done in developmental psychology, personality psychology, and social psychology, from the perspective of an interpersonal context (Tangney, 1991; Bybee, 1998). Likewise, in Japan, psychologists conduct empirical studies utilizing various guilt scales rather than through a psychoanalytic approach (Ishikawa \& Uchiyama, 2001; Arimitsu, 2002; Ohnishi, 2008).

In this article we review and relate the main psychological theories about guilt that have been studied separately. We classify guilt to various types from view point of what one feels guilty for or what kind of guilt one feels. It is important to consider affective side of guilt, but our focus in this article is what one feels guilty for, that is the problem of cognition of one's behavior. Kohlberg (1969) had such point of view and took up what reason one feels guilt as one aspect of moral development. But he didn't attach importance to guilt and his morality was limited as Gilligan (1982) criticized. We spread area of morality and consider guilt more important than Kohlberg as the problem of cognition of one's behavior. Hoffman (2000) has been considering various types of guilt relating to his developmental theory of empathy that includes cognitive point of view. Referring to Kohlberg (1969), Gilligan (1982) and Hoffman (2000), we set two criteria to classify guilt which are the problem of what one consider to feel guilty. By setting two criteria theoretically, a kind of guilt that has been little mentioned until now may come into our view. It contributes to understanding guilt in broader and deeper sense.

We argue about these types of guilt referring to psychological studies and occasionally to literary works and show that there are different types of guilt from traditional or prosperous one in psychology, and that one of which is hold by some people among Japanese who live in a culture quite different from Western culture.

\section{Psychological Theory about Guilt}

In psychology, Freud's psychoanalytic theory was the first to treat guilt as a central issue. According to Freud (1923), guilt is formed in period of Oedipal development, that is, at ages 3 or 4 years old. Children form an Oedipus complex: libido towards the mother, aggression towards the father, and anxiety about punishment for those drives. To dissolve this dangerous complex, children identify with the father, leading to the formation of the superego, which compels them to feel guilty when they deviate from parental standards. Guilt in Freud's theory is fear of punishment meted out by their father, or the emotional anxiety surrounding such punishment. 
Thus, guilt is a socializing force. But an excess of guilt leads to neurosis or mental disease.

While guilt in Freud's theory is internalized aggression towards oneself, Klein (1937) and Winnicott (1965) draw attention to the guilt deriving from aggression that infants direct towards their mothers. By attaining to Klein's depressive position or getting Winnicott's capacity for concern, infants become to realize that a good object giving them satisfaction is the identical of a bad object bringing them frustration, and that they have attacked a good object. In those theories infants feel guilty because of their aggression earlier than Freud's theory. Kosawa, a Japanese psychoanalyst, also emphasizes guilt deriving from aggression directed towards one's mother; he names it the Ajase complex. Moreover, there are other kinds of guilt that one feels or allows to be felt although the person never actually hurts another (O'Connor et al., 2000).

In social learning theory, control and restraint of deviant behavior is considered to derive from fear of punishment, similar to Freud's theory, and guilt is considered a conditioned anxiety. This theory, which makes much of cognition, is called social cognitive theory: cognition of situation and expectation of result are considered important elements. Bandura (1989) proposes that moral behavior is related to self-observation, the judgment process, and self-response. Although guilt is considered to be related to self-response, there have been few discussions about what guilt actually is.

In the sphere of developmental psychology, Piaget (1932) suggests the stage theory of morality from cognitive developmental theory which considers moral development as the problem of one's view of morality, and advocates differently from those theories above. While in heteronomous morality, which is Piaget's lower stage, one considers an act that is punished by authority to be bad, in the autonomous morality of a higher stage, the act of breaking mutual trust is considered to be bad. Piaget doesn't take it up as the problem of guilt per se, but he seems to suggest that one feels guilty when one does something anticipating punishment in the heteronomous stage, as well as when one breaks a mutual trust in the autonomous stage.

Kohlberg expands and elaborates on Piaget's theory, proposing a theory of six stages of moral development wherein moral development is a problem of rational cognition, depending upon how people think and judge moral matters. Kohlberg thinks that a moral emotion like guilt also is connected to cognition. That is, the developmental problem is not a question of the strength of guilt but rather of what situations bring about feelings of guilt or for what reason that one feels guilty that differs with the degree of cognitive development. Guilt is, therefore, what one avoids when one judges or acts in a moral context. In Kohlberg's issue scoring manual (Colby \& Kohlberg, 1987) there are issues of "Punishment and Guilt-Shame" (BI). In stage 1, a person avoids punishment by authority, similar to Freud's guilt. In stage 2, one avoids instrumental or hedonic disadvantage. $\mathrm{He}^{1)}$ feels that he was bad not because of deviating from standards but because of creating a loss. In stage 3 , one avoids disapproval from others for maintaining good relationships; therefore, guilt is anxiety for losing

1) This description is correctly "he or she", but avoiding complicated description we only describe "he" in this article. 
approval. In stage 4 one feels guilty when one fails to do one's duty or fulfill one's responsibility. At the principled level (stages 5 and 6), one feels guilty when one violates his own principles, which go on orienting to universality. In every stage a person tries to judge by his own conception of justice and feels guilty when he judges or behaves contrary to these principles. At every stage, guilt is a negative emotion of self-blame because of one's failure to adhere to his own principles, though guilt differs with the degree of development.

In Kohlberg's theory the direction of development is from a narrow perspective, by which one regards justice from only his own viewpoint, to an abstract or formal perspective, by which one considers and integrates various viewpoints and situations. Gilligan (1982) criticizes Kohlberg's theory for rating those who judge using empathy and care for others close to them as developmentally low level, stage 3 . She thinks there are other stage sequence in moral development that are alternatives to Kohlberg's stages and proposes the morality of care and responsibility. In this morality, an individual does not judge in an abstract and formal way but rather tries to care for others in close relationships, to respond to the needs of others, and feels guilty when he fails to respond to others or injures them. Hoffman (2000) investigates the development of empathy and advocates a theory of empathy-based guilt that is felt when one regards himself to be the origin of another's distress, a guilt that differs from fear-based guilt. $\mathrm{He}$ also explores the guilt of the innocent bystander and survivor's guilt that people sometimes experience despite no wrongdoing. He thinks that survivor's guilt may come from the unfairness when one considers social balance. "If an individual feels that he has done better than other, then he may feel guilty over having gotten more than his fair share and having taken the excess portion from others in the process" (p. 189).

The 1990s saw an increase in studies of guilt using the interpersonal approach; that is, guilt was looked upon as emotions experienced based on a consequence of interpersonal relations or interpersonal phenomena between persons, than emotions experienced just inside him, intrapsychic process (Tangney, 1991; Baumeister et al., 1994). Guilt felt in relation to others was a common theme, especially examining the similarity and difference between shame and guilt, both negative emotions, through analysis of the relation between sub-scales of psychopathology or personality traits (Tangney, 1998). As well, there were also studies about the development of guilt or conscience (Hoffman, 2000; Kochanska, Gross, Lin, \& Nichols, 2002; Thompson, Meyer, \& McGinley, 2006).

\section{Four Types of Guilt}

The review of the research above reveals many contrasting distinctions surrounding guilt as follows: 1) Guilt based on super-ego vs. guilt based on relatedness; 2) guilt felt because one breaks one's framework of morality vs. guilt felt because one injures another; 3) fear- and anxiety-based guilt where one fears punishment or blame vs. empathy-based guilt which arises from empathy for others in distress. In each case, cognition is concerned with which aspects a person focuses on-himself or the other. In this article, we established two criteria for the classification of guilt. The first criterion is whether there is direct interaction with others, i.e., one feels guilty for the person to whom one directs his act, or one feels guilty without direct interaction with others. The 
second is the criterion of social balance, that is, whether one considers only his own acts (unidirectional) or compares his behavior with the behavior of others and tries to keep a balance (reciprocal). These two criteria allow the identification of four types of guilt, as illustrated in Figure 1.

The first type of guilt is the guilt felt because of what one has done rather than on recognition of how one's behavior has affected the other. The second type of guilt is that which focuses on the other whom one has injured or has influenced. These two types are basically unidirectional, but the third and fourth types include a comparison of one's own behavior to the behavior of the other. The third type is the guilt which results from imbalance in an interaction between one person and the other. The fourth is the guilt which results from imbalance between one person and another who has no direct interaction with him.

Because the first type of guilt are often documented and discussed in earlier studies, which we refer to in the previous section, we will mention it only briefly. Instead, we focus mainly on the second type of guilt of which there has been many studies recently, and on the third and fourth types of guilt, of which there have been few studies so far.

\section{The First and Second Types of Guilt}

The first type of guilt arises from a focus on what we have done and whether we believe that our behavior meets a set standard or not. Freud's superego evokes this type of guilt, based on whether we consider that we were punished or not, in accord with an internalized standard derived from the symbolic father figure, and Kohlberg's guilt is also such self-reproach for doing wrong based on one's own conception of justice, though it differs according to one's stage of development. Kohlberg thinks that we experience self-reproach as we consider what our behavior brings to others and to society. Though a consideration develops from a narrow perspective to a broader one, the basis of self-reproach depends upon whether we adhere to or violate a standard

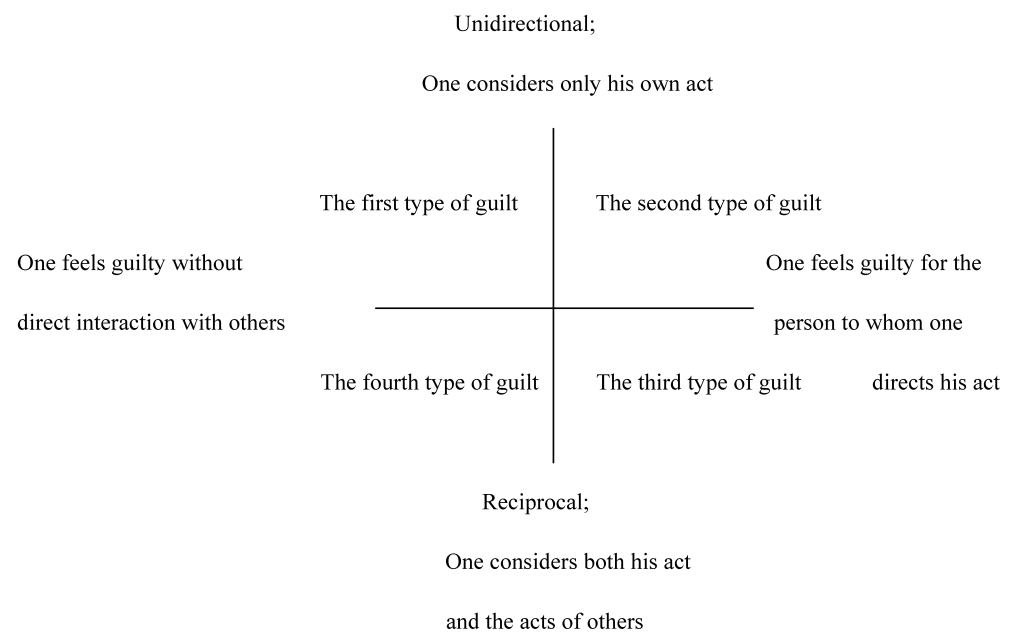

Horizontal axis: whether there is direct interaction with others,

Vertical axis: whether one considers only his own act or both his act and the acts of others

Figure 1 Four types of guilt 
of justice which we construct by ourselves. This type of self-reproach is not equal to the fear- or anxiety-oriented guilt of a lower level, but it is anxiety or pain of contravening our own conception of justice.

The second type of guilt is the guilt produced by a focus on the person whom we may have injured rather than what we have done. Gilligan's morality of care and responsibility and Hoffman's empathybased guilt are examples of this type of guilt, which arises from a focus on the influence or effect we have on others and is based on empathy and a sense of responsibility for responding to the expectations or feelings of others. Relatednessbased guilt in psychoanalysis theory also seems to be this type of guilt which arises from a realization of the damage one's aggression has brought, though one had not actually considered the expectations or feelings of the injured person for it arises in early infancy.

The second type of guilt is interpersonal guilt; however, not all guilt coming from a relationship to another is this type. In Japan, for example, people are apt to experience guilt in relation to other people, in contrast to people in Western Europe who are apt to experience guilt in relation to God, as Benedict (1946) described and as Yamagishi (1976, 1995) empirically showed with Kohlberg's method. Nonetheless, all Japanese do not necessarily have this second type of guilt. Japanese people surely value decency or an obligation to others, in Japanese words "giri" and "ninjo," which some use for moral reasoning. In this case, they may be less concerned with how others have been affected by their behavior than with avoiding selfreproach by not violating some standard of justice.

In Kohlberg's hypothetical dilemma where one is demanded to consider a fair solution, a person who employs Gilligan's morality of care and responsibility thinks about each circumstance and the needs of the other person. In an actual dilemma, that person cares more and judges his actions from the point of view of injury to others through his behavior or by a failure to discharge a responsibility to others.

Gilligan, whose claim of this second type of morality is widely accepted, proposed that this type of morality is an alternative path of development constructed by interpersonal experience which a female is apt to have when only Kohlberg's morality was considered. There has been much controversy about these two kinds of morality, engendering many theoretical and empirical studies in the last twenty years (Walker, 2006). These empirical studies show that there is little gender difference in moral orientation and that both males and females are aprt to use both orientations to justice and to care (Walker, 2006). The factor that determines which orientation is used is, in many cases, the type or nature of the moral problem (for example, hypothetical vs. real life; impersonal vs. personal dilemma).

These two orientations to morality - that is, the two types of guilt - are often contrasted in literary works. Two contemporary literary works, Wild Swans (Chang, 1991) and Silence (Endo, 1966), offer good examples. In Wild Swans, the moral dilemma is described as a problem of gender; in Silence, as a situational problem, in which one person may have both orientations to morality but uses one or the other depending on the context.

In Wild Swans, an autobiographical family history, Chinese writer Jung Chang describes a discussion between her parents, both of them are executives of the Chinese Communist Party, 
about a letter which her father plans to write to Mao Zedong concerning the destructive acts of the Great Cultural Revolution:

In a tone of despair he (my father) said, 'What else can I do? What alternatives do I have? I must speak up. It might help. And I must do it even if just for my conscience.'

'Why is your conscience so important?' my mother said. 'More than your children? Do you want them to become "blacks"?'

There was a long pause. Then my father said hesitantly, 'I suppose you must divorce me and bring up the children your way.' (Chang, 1991, p. 430)

The father, who makes all possible efforts to stay true to his own principles, carries out what he considers to be right universally. He acts upon his strong belief that someone must prevent destructive violence to realize justice in society as a whole. On the other hand, after the mother considers the effect of their behavior on her children, only then does she determine the best way to proceed. Rather than abiding by some abstract principle, she judges based on care for people whom she is personally responsible. The father exhibits the first type of guilt; the mother, the second type. The two types of guilt or two moralities manifested in this discussion are related to gender, confirming Gilligan's hypothesis.

In Silence (Endo, 1966), a novel by the famous Japanese writer Shusaku Endo, it is said that Christ's existence and love is described, but we can read in it also the confrontation between the two types of morality. The story concerns a plate, marked with a crucifix, upon which people are forced to tread as a repudiation of Christianity in a period of suppression of the Christians in 17 century in Japan. Those who refuse to tread on the plate are condemned to death. The story unfolds around Portuguese priests, Japanese peasants, and government officials, and the priests are put to the test. It is assumed that the priests, who propagate their faith in Christianity at the risk of their lives, will act on their principles and, of course, refuse to step on a plate with a crucifix on it. But the priest Ferreira, adored by everyone, steps on the plate; moreover, the priest Rodrigues, who criticized Ferreira, also does. It is an historical fact that the priests, by this act of surrender, were able to avoid torture but made it impossible no longer to propagate Christianity in Japan thereafter. Their act was a renunciation of their mission and a betrayal of their God.

But Endo describes their act of defeat as a way to save the peasants who would otherwise have continued to suffer torture for priests who refused to step on the plate rather than as an act of weakness. The priests became to think that stepping on the plate was the acts of love. Ferreira said to Rodrigues "For love Christ would have apostatized. Even if it meant giving up everything he had (p. 170)". The priests' purpose changed from following their faith and propagating Christianity, which is expected to be a realization of justice, to shouldering their responsibility for people who would suffer because of the priests' behavior. Priests who seek to behave according to a universal value, a high level of morality, throw away that value and choose to behave according to the expectations of others in close relationship to avoid injuring others, even if their behavior seems to be a betrayal of God. Their choices to save others may be supposed to be a kind of corruption, or regression to a low level in Kohlberg's morality. 
However, it is an alternative morality, motivated by different type of guilt. In this story there also are two types of guilt: a pain of violating one's own principles or God's doctrine (the first type of guilt); and a pain of injuring others with whom they are in relationship (the second type of guilt). The two types of guilt are not related to gender. Instead, one person, possessing both, chooses to act on one or the other corresponding to the actual situation.

\section{The Third Type of Guilt}

When we have guilt, we may try to mitigate it through atonement. We apologize to the person whom we hurt, do penance, behave prosocially, or try to obtain forgiveness through confession to God. All of these efforts are aimed at modifying the disequilibrium, or imbalance, we feel as a result of our wrongdoing.

This third type of guilt is derived from the disequilibrium in an interaction between oneself and another person. It comes about not only when we injure others, but also when we feel uncomfortable because of a sense of imbalance arising when we receive something good but others don't. It also develops when the equilibrium of exchangeability or reciprocity is upset, for example, when others do something good for us, but we fail to return the favor. Such psychological indebtedness also leads us to apologize or make some sort of compensation. Arimitsu's subscale of debt feeling toward others in Situational Guilt Inventory (Arimitsu, 2002), which includes such items as feeling guilty when "I waste other's kindness" or "others accept me in spite of my selfishness," reflects this third type of guilt.

A typical example of the third type of guilt that is derived disequilibrium of interaction between oneself and others is the Ajase complex, first proposed by psychoanalyst Kosawa in 1920 as feelings proper to Japanese. Although he showed the article to Freud, Freud saw no value in it (Okonogi, 1979). Nonetheless, Okonogi (1979, 2001) took it up as an important concept. The mechanisms of these two types of guilt, the Oedipus complex and the Ajase complex, are quite different. Whereas the Oedipus complex is conflict between a father and a child, the Ajase complex derives from conflict between a mother and a child. With the former, a child fears being attacked by the father; with the latter, the child regrets his aggression towards the mother by her forgiveness (Okonogi, 2001).

Ajase is a character in a Buddhist narrative. Because he detested the egoistic behavior of his mother in trying to kill him at birth to gain the favor of her husband, the king, Ajase tried to kill both his father and mother. Although a governmental minister eventually persuaded him not to do so, he still succumbed to a serious disease because of guilt for his murderous intention. $\mathrm{He}$ recovered his health through his mother's devotion. Afterwards, he made a confession and finally was redeemed by the Buddha. The main theme is the imbalance between Ajase and his mother. Though Ajase has hatred and intends to kill his mother, she forgives and devotes to him. That disequilibrium caused Ajase to feel remorse, creating restraints on his behavior. That is, his disequilibrium led him to internalize a moral standard differently from that ascribed to the Oedipus complex.

Another example of the third type of guilt derived from the imbalance of interactions between oneself and others is represented in Naikan therapy (Miki, 1976), which is descended 
from the introspection carried out during training in Jodoshinshu, a school of Buddhism in Japan. Naikan therapy, developed in Japan originally, requires clients to carefully examine their behavior in the past towards a particular person, for example, their mother, from three aspects: 1) what they were given and how they were helped; 2) what they returned to the person; 3) what they cause trouble for the person. In many cases the clients discovered that they had failed to return favors or kindnesses despite having been given much. Many came to feel thankfulness, as well as self-reproach for repaying kindness with ingratitude. It is generally thought that the guilt derived from the disequilibrium in the interaction between the self and the other, as well as the awareness of love given to them, found through introspection, changes their cognition and behavior.

Shusaku Endo seems to be describing this third type of guilt in his literal works Upon the Dead Sea (Endo, 1973a) and A Life of Jesus (Endo, $1973 \mathrm{~b}$ ), both of which center on the unique figure of Jesus Christ and describe the religious climate different from Western Europe.

When a crowd demanded miracles of Christ because he was regarded as a Savior, he could nothing but remain, in sympathy, by the side of the suffering person. He said, "I can't cure your disease, but I want to bear your suffering together with you, tonight, tomorrow night, and the next night. I want to bear it with you whenever you have suffering."

Christ's behavior disappointed the crowd because it seemed for them that he only suffered together with the afflicted person, quite powerless and impotent. The people became angry that he had betrayed the expectations they had had of a
Savior; therefore, they deserted him and took part in crucifying him. Christ died a painful and miserable death on the Cross for love of them. But by this fact they could not forget Christ because of their feelings of guilt for betraying him although he loved them and had died for them. A man, whom Christ cared for all the time he was sick, saying gently "I am always beside you. You are not alone", and who became to adore Christ, also deserted him. Afterwards he repented, saying "I deserted him, though he never deserted me." Through such repent the disciples who had been cowards became passionate missionaries, and the devotion of the crowd grew.

Endo's interpretation is not necessarily the interpretation of Japanese in general. While these two works have been read popularly, some persons criticize on his view. (Endo wrote in postscript that many priests and theologians, even Japanese, would criticize on his view.) But his interpretation is easy to understand and has appeal to Japanese people.

Endo's faith may be described as maternal, in contrast to the paternal nature of the faith of Western people. In the paternal model, the father deals with his children by revisiting past behaviors, treating the children as independent individuals and giving them feedback accordingly. In the maternal model, the mother accepts her children, continuing to give to them and to love them no matter what they do (Kawai, 1976). The maternal figure does not demand equilibrium in interactions with her children, and the ensuing disequilibrium engenders in her children the third type of guilt.

The Ajase complex and Naikan therapy, both of which were originally proposed in Japan, along with Endo's peculiarly Japanese interpretation of 
Christ, an interpretation differing from the traditional Western one, suggest that Japanese people are apt to have the third type of guilt adding to the first and the second type of guilt.

In summary, a person feels the third type of guilt when there are interactions between oneself and others, resulting in a sense of imbalance. Examples illustrate the imbalanced situations a person has injured the other person, but he or she was not blamed for the wrongdoing but is forgiven although his behavior; situations in which the other person continues to love him although the love is not reciprocated; and cases in which the other does not desert one, although he had deserted that other person.

\section{The Fourth Type of Guilt}

The first three types of guilt, mentioned above, arise from self-reproach because of deviation from a standard or from injuring others; however, a feeling of guilt may occur even in the absence of such behavior. In his review of survivor's guilt in Auschwitz and Hiroshima, Baumeister et al. (1994) suggests that genuine inequality can bring about feelings of guilt. People like to be dealt with fairly: they feel anger or jealousy when they get less than others; they feel guilty when they get more. In his studies about Hiroshima and about veterans of the Viet Nam War, Lifton (1976) reports the belief of survivors that they had continued to live at the cost of the sacrifice of lives of others. O'Connor et al. (2000) also argues for the guilt for injuring others, which stems from a comparison of one's own sense of satisfaction to that of others.

Regarding survivor guilt, Hoffman (2000) argues that "people feel guilty when they survive natural disasters (earthquakes, floods, fires), man- made catastrophes (Hiroshima, the Holocaust), fellow soldiers dying in battle, terrorist bombings, plane or car accidents, etc." (p. 188). He cites a survivor's words, such as, "Why me, why was I saved and not somebody else?" (p. 188). He also mentions guilt over affluence coming from an awareness of the inequality between a person's own good life and the misery of the other, as well as guilt over the relative advantage that one enjoys from being in a privileged situation compared with other people.

These types of feelings comprise the fourth type of guilt. It is felt when disequilibrium arises from a comparison of behavior of the self and the other. There are two cases of disequilibrium in behavior of the self and the other: one is the case of one person interacting with the other, and the other occurs when there is disequilibrium in two relationships which the person and the other have to the same third person, or anything else. The former is the third type of guilt, and the latter, the fourth. We feel the fourth type of guilt when these two relationships are different, and we are advantaged unfairly. In addition, the one who feels guilty may include any person, not only those in close relationship to the person but also those in no relationship whatsoever or those who are present only in abstraction.

This type of guilt is akin to that measured by certain items on Ohnishi's "guilt of excessive gain" that is a subscale of Trait Guilt Scale like as "It makes me uncomfortable to receive better treatment than the people I am with.” (Ohnishi, 2008), or to items on O'Connor's survivor guilt like as "I am disturbed at the sight of the poor." (O’Connor, 2000).

A poem dedicated to victims of leprosy by Kamiya (2004), a psychiatrist, offers an example of 
the fourth type of guilt.

Why you, not me? You took our place, you were privileged in everything and suffered infernal pain in our place. Please forgive us, patients with leprosy. (pp. 138-139)

There were other examples of writers before World War II, who belonged to the propertied class and felt guilty because of their awareness of the poverty of the lives of the others. The lives of these writers were influenced by that guilt. One of motives driving student movements of the 1960s is supposed to be the fourth type of guilt brought about by the realization of how privileged the students were.

In Japan the fourth type of guilt is not common and there has rarely been mentioned. But Japanese people recently began using the phrase "survivor's guilt" in connection with the Great Hanshin Earthquake in 1995 and the derailment accident on the Fukuchiyama line in 2005 (Ikeno, 2000; The Nishinippon Newspaper, 2005), and used also in the Great East Japan Earthquake in 2011. But these accidents are also considered to cause one type of Post Traumatic Stress Disorder (PTSD), which one suffers as he attempts to recover from a sense of helplessness stemming from having failed to do anything for the deceased. Thus, such guilt may be viewed as somewhat different from the fourth type of guilt deriving from disequilibrium. It should be examined more.

\section{Conclusion}

The purpose of this study was to review and classify the main psychological theories about guilt from cognitive point of view, what one feels guilty for. We identified four groups by using two criteria as follows: The first criterion is based on the person for whom one feels guilty, and the second criterion is based on whether one considers only his own act or compares his act with the acts of others.

The first type of guilt, classified by two criteria, is the guilt felt because of what one has done rather than on a recognition of how one's behavior has affected the other. The judgment that he was wrong is based on, an established standard of behavior, including religious beliefs, or his own principles. Many earlier psychological studies have documented this type of guilt. The second type of guilt is that which centers on the other whom one has injured or has influenced, in relation with others. This type is considered from the perspective of an interpersonal context and recently many studies of social and developmental psychology take up this type of guilt.

The first and second types of guilt are basically unidirectional, but the third and fourth types include a comparison of one's own behavior to the behavior of the other. The third type is the guilt which results from a disequilibrium in an interaction between one person and the other. The fourth is the guilt which results from a disequilibrium between one person and another who has no particular relationship to him. Though there have been a few studies of these types of guilt, recently the fourth type has come to be referred to as "survivor's guilt."

The third type has been referred mainly in Japan. It is expressed in the Ajase complex and Naikan therapy, both of which developed originally in Japan. The third type is also described in Shusaku Endo's literary works, which depict the figure of Christ as different from Western inter- 
pretation. These examples support the notion that some people among Japanese are apt to feel the third type of guilt, and that is suggested to be related to Japanese culture.

In this article we classify guilt to four types by using two cognitive criteria for what one feels guilty. We identify and relate various types of guilt which have been studied in psychology and show that there are different types of guilt from vigorously studied one, and that one of which is apt to be hold by some people among Japanese who live in a culture quite different from Western culture.

Recently many studies of guilt have been done in developmental psychology, personality psychology, and social psychology, but the third and the fourth types of guilt have been little mentioned until now. But by setting types of guilt theoretically based on two criteria, these types of guilt may come into our view. It contributes to understanding guilt in broader and deeper sense. It is necessary to investigate their onset, their development, and experiences that engender them from the developmental and cultural perspectives relating to other types of guilt. We think that doing so we will reconsider the concept of guilt and make the research in richer and more comprehensive perspective.

\section{Reference}

Arimitsu, K. (2002). Structure of guilt eliciting situations in Japanese adolescents. Japanese Journal of Psychology, 73, 148-156.

Bandura, A. (1989). Social cognitive theory of moral thought and action. In W. M. Kurtines \& J. L. Gewirtz (Eds.), Moral behavior and development: Advances in theory, research and appliications. Hilsdale NJ: LEA. pp. 71-129.

Baumeister, R. F., Stillwell, A. M., \& Heatherton, T. F. (1994). Guilt: An interpersonal approach. Psychological Bulletin, 115, 243-267.
Benedict, R. (1946). The chrysanthemum and the sword. Boston: Houghton Mifflin Co. (Trs. by M. Hasegawa (2005). Tokyo: Kodansha.)

Bybee, J. (1998). Preface. In J. Bybee (Ed.), Guilt and children. San Diego: Academic Press. pp. 13-22.

Chang, J. (1991). Wild swans: Three daughters of China. New York: Simon \& Schuster.

Colby, A., \& Kohlberg, L. (1987). The measurement of moral jurgement. Vol II. Standard issue scoring manual. Cambridge: Cambridge University. Press.

Endo, S. (1966). Silence. Tokyo: Shinchosha Publishing. (Trs. in English by W. Johnston (1980). Marlboro: Taplinger Publishing Company.)

Endo, S. (1973a). Upon the dead sea. Tokyo: Shinchosha Publishing.

Endo, S. (1973b). A life of Jesus. Tokyo: Shinchosha Publishing.

Ferguson, T. J., Stegge, H., Miller, E. R., \& Olsen, M. E. (1999). Guilt, shame, and symptoms in children. Developmental Psychology, 35, 347-357.

Freud, S. (1923). The ego and the id and other works. (Trs. by J. Strachey (1961). London: Hogarth Press.)

Gilligan, C. (1982). In a different voice: Psychological theory and women's development. Cambridge: Harvard University Press.

Hoffman, M. L. (2000). Empathy and moral development: Implications for caring and justice. Cambridge: Cambridge University Press.

Ikeno, S. (2000). Cultural roles and coping processes among the survivors of the Hanshin-Awaji (Kobe) Earthquake, January 17, 1995: An ethnographic approach. Kwansei Gakuin University Sociology Department Studies, 85, 81-100.

Ishikawa, T., \& Uchiyama, I. (2001). Empathy and roletaking ability: Guilt feelings in 5-year-old preschoolers. Japanese Journal of Educational Psychology, 49, 60-68.

Kamiya, M. (2004). Gazing at human beings. Tokyo: Misuzu Shobo.

Kawai, H. (1976). Pathology of maternal society Japan. Tokyo: Chuuoukoron-Shinsha.

Klein, M. (1937). Love, guilt and reparation. London: Hogarth Press. (Trs. by Y. Okumura (1983). Tokyo: Seishin Shobo.)

Kohlberg, L. (1969). Stage and sequence: The cognitive developmental approach to socialization. In D. A. 
Goslin (Ed.), Handbook of socialization: Theory and research. Chicago: Rand McNally. pp 347-480.

Kochanska, G., Gross, J. N., Lin, M. H., \& Nichols, K. E. (2002). Guilt in young children: Development, determinants and relations with a broader system of standards. Child Development, 73, 461-482.

Lewis, M., Sullivan, M. W., Stanger, C., \& Weiss, W. (1989). Self development and self-conscious emotions. Child Development, 60, 146-156.

Lifton, R. J. (1976). The life of the self: Toward a new psychology. New York: Basic Books.

Miki, Y. (1976). Introduction to Naikan therapy: The world of Japanese search for one's self. Osaka: Sogensha.

O'connor, L. E., Berry, J. W., \& Weiss, J. (2000). Survivor guilt, submissive behavior and evolutionary theory: The down-side of winning in social comparison. British Journal of Medical Psychology, 73, 519-530.

Ohnishi, M. (2008). Structure of trait guilt in adolescents: Conceptualization of guilt and development of trait guilt scale based on psychoanalytic theory. Japanese Journal of Personality, 16, 171-184.

Okonogi, K. (1979). Japanese object relation from the point of Ajase complex. L'esprit d'aujourd'hui, 148, 228-247. Tokyo: Shibundo.

Okonogi, K. (2001). A development of the theory of Ajase complex. In K. Okonogi \& O. Kitayama (Eds.), (2001). Ajase complex. Osaka: Sogensha. pp. 4-58.

Piaget, J. (1932). The moral judgment of the child. New York: Free Press.
Tangney, J. P. (1991). Moral affect: The good, the bad, and the ugly. Journal of Personality and Social Psychology, 61, 598-607.

Tangney, J. P. (1998). How does guilt differ from shame? In J. Bybee (Ed.), Guilt and children. New York: Academic Press. pp. 1-17.

The Nishinippon Newspaper (2005). 2005, 5, 22. Morning paper.

Thompson, R. A., Meyer, S., \& McGinley, M. (2006). Understanding values in relationships: The development of conscience. In M. Killen \& J. Smetana (Eds.), Handbook of moral development. Hilsdale, NJ: Lawrence Erlbaum Associates. pp. 267-297.

Walker, L. J. (2006). Gender and morality. In M. Killen, \& J. Smetana (Eds.), Handbook of moral development. Hilsdale, NJ: Lawrence Erlbaum Associates. pp. 93-118.

Winnicott, D. W. (1965). The maturational processes and the facilitating environment. London: Hogarth Press. (Trs. by S. Ushijima (1977). Tokyo: Iwasaki Gakujutu Shuppansya.)

Yamagishi, A. (1976). The development of moral judgement. Japanese Journal of Educational Psychology, 24, 29-38.

Yamagishi, A. (1995). Empirical and theoretical studies about moral judgement. Tokyo: Kazama shobo.

Yamagishi, A. (2002). The developmental meaning of the dulution of social rule consciousness among adolescents in present Japan. Jounal of Juntendo Medical College of Nursing, 13, 49-58.

-2012.4.22受理, 2013.10.18受理一 